\title{
Medical Dominance in Nursing Education: Qualitative content analysis
}

\author{
Research Article
}

\section{Mahdi Moosaeifard1, Kourosh Zarea², Masoud Sirati Nir³, Mohammadreza Dinmohammadi ${ }^{4}$, Abolfazl Rahimi ${ }^{5,6 *}$}

\author{
1. PhD Candidate in Nursing, Nursing and Midwifery School, \\ Ahvaz Jundishapur University of Medical Sciences, Ahvaz, Iran. \\ 2. $\mathrm{PhD}$ in Nursing, Associate Professor, Nursing Care Research Center in Chronic Diseases, \\ Nursing and Midwifery School, Ahvaz Jundishapur University of Medical Sciences, Ahvaz, Iran. \\ 3. Behavioral Sciences Research Center, Baqiyatallah University of Medical Sciences, Tehran, Iran. \\ 4. $\mathrm{PhD}$ in Nursing, Associate professor, Critical Care Nursing Department, Nursing and Midwifery School, \\ Zanjan University of Medical Sciences, Zanjan, Iran. \\ 5. PhD, Associate Professor, Health Research Center, Nursing Faculty, Baqiyatallah University of Medical Sciences, \\ Tehran, Islamic Republic of Iran. \\ 6. Medicine, Quran and Hadith Research Center, Baqiyatallah University of Medical Sciences, Tehran, Iran.
}

\begin{abstract}
Background: Training specialist manpower requires social justice in higher education and inequality leads to the emergence of hierarchies of power and types of dominant or dominated groups. Aim: The aim of the present study was to explain the perceptions and experiences of the heads of nursing departments of Iranian nursing schools regarding medical dominance in nursing education. Methods: The present study was a conventional content analysis. Data collection was carried out using purposeful sampling and in-depth semi-structured interviews with 24 participants. The data analysis process was performed according to Graneheim and Lundman's qualitative content analysis (2004). Findings: Data analysis led to the emergence of the theme of "Medical dominance in nursing education" and the three main categories of "physician-centered university education", "weakened educational status", and "belittling nursing education in medical system". Conclusion: The findings of the present study indicated that physicians enjoy special and superior position in the structure of the Ministry of Health and Medical Education of Iran. Physicians manage the entire system including medical education due to their greater power in managing the system at all micro and macro levels. Thus, other disciplines including nursing education, which are closely related to medicine, are highly ignored.
\end{abstract}

Key Words: Educational management, Dominance, Nursing education, Medical dominance, Qualitative content analysis, Discrimination.

\section{Introduction}

Higher education and universities are considered as key players for sustainable development at the national and international levels $(1,2)$. Education is becoming a global service in the competitive knowledge market (3). The role of education is vital to nursing progress (4). Although nursing education has a positive trend in Iran, it still faces multiple challenges (5). Discrimination and inequality are one of the major challenges facing nursing $(6,7)$. Bullying has long been widespread in nursing (8). All healthcare providers face discrimination. Discrimination between nurses and

* Corresponding Author:

\section{Abolfazl Rahimi,}

$\mathrm{PhD}$ in Nursing, Associate professor,

Baqiyatallah University of Medical Sciences,

Tehran, Iran.

Email id-fazel1234@yahoo.com physicians is prevalent (9) and is the main concern of nurses in collaborative work (10). The superiority of physicians to nurses and the medical model of care have made nurses obedient (11). In most Asian, African and Australian countries, the health system is under the dominance and management of physicians (12). There is also a distinction between medical and nursing fields in Italy (13). Physicians dominate not only nursing but the entire health system and receive unique facilities (14).

Nursing education faces many challenges at the regional and world level today (15). The concepts of social justice in the nursing curriculum focus on equality and diversity but have not sufficiently addressed the dimensions of power and structures of dominance (16). Disrespect in higher education, including nursing, has become a growing and frustrating concern (17). Most students witness systematic discrimination and bullying in clinical centers (6) and complain of discrimination between themselves and students in other disciplines $(18,19)$. Compared to medical students, nursing students are 
considered to be of relatively low status (20). Educators, nurse managers, and clinical staff should end bullying behaviors and modify the environment using relevant strategies $(21)$.

Numerous studies have shown discrimination between physicians and nurses in Iran and other countries, but so far, there has been no qualitative study on the dominance of medical education in nursing education from the perspective of heads of nursing departments as experts in nursing education in Iran. Therefore, the aim of the present study was to explain the medical dominance in nursing education to achieve a deep understanding of the dimension of the subject matter.

\section{Methods}

This study is part of the author's PhD dissertation, which deals with the phenomenon of medical dominance in nursing education after being approved by the Ethics Committee of Baqiyatallah University of Medical Sciences with No. 9121151003.

\section{Selection of participants and data collection}

The study population included twenty-four participants, including 18 heads of nursing departments, 2 heads of nursing schools, one deputy for education and 3 faculty members of nursing department (Table 1). Data collection was carried out through semi-structured individual interviews and purposeful sampling and lasted for 26 months. The study population included key participants with rich educational experiences who seemed to be the heads of departments with at least one year of work experience. At the beginning of each interview, the subject of the study was coordinated with the interviewee, the interview appointment was determined, and written consent was obtained before each interview. All interviews were conducted in one session at an average time of 60 minutes, except for one interview. All interviews were conducted by a researcher and a bilingual translator was used to ensure the meanings and concepts derived from the article.

\section{Table 1: Demographic information of participants}

\begin{tabular}{|c|c|c|c|c|}
\hline Age & Sex & Academic rank & Level of education & $\begin{array}{l}\text { Years of experience of the heads of } \\
\text { departments (Months) }\end{array}$ \\
\hline 48 & Female & Assistant Professor & $\mathrm{PhD}$ & 50 \\
\hline 51 & Female & Educator & M.A & 48 \\
\hline 48 & Female & Educator & M.A & 24 \\
\hline 51 & Female & Educator & M.A & 32 \\
\hline 51 & Female & Associate Professor & $\mathrm{PhD}$ & 36 \\
\hline 62 & Male & Associate Professor & $\mathrm{PhD}$ & 260 \\
\hline 47 & Female & Assistant Professor & $\mathrm{PhD}$ & 44 \\
\hline 46 & Female & Assistant Professor & $\mathrm{PhD}$ & 27 \\
\hline 57 & Male & Associate Professor & $\mathrm{PhD}$ & 48 \\
\hline 45 & Female & Educator & M.A & 24 \\
\hline 59 & Male & Assistant Professor & $\mathrm{PhD}$ & 72 \\
\hline 53 & Male & Assistant Professor & $\mathrm{PhD}$ & 30 \\
\hline 44 & Female & Assistant Professor & $\mathrm{PhD}$ & 45 \\
\hline 63 & Male & Assistant Professor & $\mathrm{PhD}$ & 60 \\
\hline 35 & Female & Educator & M.A & 19 \\
\hline 37 & Male & Educator & M.A & 60 \\
\hline 33 & Female & Educator & M.A & 42 \\
\hline 48 & Male & Professor & $\mathrm{PhD}$ & 24 \\
\hline 51 & Male & Professor & $\mathrm{PhD}$ & 28 \\
\hline 44 & Female & Assistant Professor & $\mathrm{PhD}$ & 24 \\
\hline 55 & Male & Educator & M.A & 120 \\
\hline 34 & Male & Educator & M.A & Department member \\
\hline 45 & Female & Educator & M.A & Department member \\
\hline 40 & Female & Educator & M.A & Department member \\
\hline
\end{tabular}

\section{Data analysis}

Data analysis was carried out using conventional content analysis using the method developed by Landman and Graneheim (2004), so, the interviews were immediately typed and repeatedly studied to gain a better understanding of the participants' experiences. The data were then converted into meaning units and assigned appropriate codes. The codes were divided into subcategories and categories based on similarities and differences, and were abstracted based on their latent meanings, and were then assigned relevant titles (Table 2). MAXQDA (ver.10) software was used for data classification and management.

\section{Trustworthiness}

Guba and Lincoln's (1985) criteria were used to ensure the trustworthiness of the study. Credibility of the findings was ensured through long-term involvement and immersion in data, member checking, discussion with research team members, and the opinions of several colleagues familiar with the qualitative research method. During the interviews, the researcher also repeatedly summarized and repeated the participants' statements to clarify what they exactly 
meant. Transferability was also taken into account by proving a rich description of data and targeted sampling with maximum variation. To this end, a detailed description of the data collection and analysis processes is also provided. To take into consider the conformability criterion, we used opinions of two professors who were familiar with qualitative research and did not participate in this study. To ensure dependability and the possibility of external audit, all stages of the research were also described in a step-bystep manner and were also reviewed by the supervisor, readers, and experts.

\section{Ethical considerations}

The present study was approved by the Ethics Committee of Baqiyatallah University of Medical Sciences with No. 9121151003. Ethical considerations included explaining the objectives of the study to the participants, obtaining permission to record the interviews and publishing the findings, and obtaining written consent prior to each interview. Participants were justified concerning their willingness to participate in the study and the option to withdraw from the study at any time. They were assured of anonymity and confidentiality of findings.

\section{Findings}

Data analysis led to extraction of the main theme "Medical dominance in nursing education" and the three main categories according to Table 2.

Table 2: Extracted theme and categories

\begin{tabular}{|l|l|l|}
$\begin{array}{l}\text { Main theme } \\
\text { Medical } \\
\text { dominance in } \\
\text { nursing } \\
\text { education }\end{array}$ & $\begin{array}{l}\text { Main category } \\
\text { Physician- } \\
\text { centered } \\
\text { university } \\
\text { education }\end{array}$ & $\begin{array}{l}\text { Nursing education } \\
\text { under the rule of } \\
\text { physicians }\end{array}$ \\
\hline $\begin{array}{l}\text { Medical dominance, a } \\
\text { barrier to nursing } \\
\text { education } \\
\text { advancement }\end{array}$ \\
\hline $\begin{array}{l}\text { Weakened } \\
\text { educational } \\
\text { status }\end{array}$ & $\begin{array}{l}\text { Problems made by } \\
\text { medical school in the } \\
\text { path of nursing } \\
\text { education }\end{array}$ \\
\hline $\begin{array}{l}\text { Belittling } \\
\text { nursing } \\
\text { education in } \\
\text { medical system }\end{array}$ & $\begin{array}{l}\text { Weakened } \\
\text { professional status } \\
\text { Denied sabbaticals } \\
\text { Triviality of nursing } \\
\text { education problems } \\
\text { for authorities and } \\
\text { system }\end{array}$ \\
\hline & $\begin{array}{l}\text { Little responsibility } \\
\text { towards nursing } \\
\text { education on the part } \\
\text { of the university }\end{array}$ \\
\hline & $\begin{array}{l}\text { Poor alignment with } \\
\text { nursing education on } \\
\text { the part of the } \\
\text { university }\end{array}$ \\
\hline & & \\
& &
\end{tabular}

\section{Physician-centered university education}

According to the findings of the present study, one of the major challenges found in nursing education was "physician-centered university education" which consists of three subcategories of "medical dominance on nursing education", "medical dominance, a barrier to nursing education growth" and "problems made by medical faculty in nursing education process".

\section{Nursing education under the rule of physicians}

One of the examples of medical dominance in nursing education includes medical dominance in M.A nursing education, which is contrary to the consent of the nursing group and has consequently restricted nursing education for M.A students and had virtually marginalized them.

One participant said:

"We have an NICU major at M.A level. The theses of the students studying this major are supervised by physicians. Although we actually supervise the theses, physicians act as if they have done it. (p12)"

Another participant said:

"This discipline was requested by the Vice Chancellor for education without informing the nursing department and after receiving the approval of the discipline from the relevant ministry, I was notified (p24)"

Another participant said:

"Physicians were practitioners of the discipline from the very beginning $(p 8)$ "

Clinical education is the most challenging part of nursing education because all of the medical facilities and authorities are at the service of physicians due to their presence in the management positions of the centers and the nursing education consequently faces many problems. Here is an example of the participants' statements:

"I wanted to take my nursing students to the skill lab of the hospital in order to teach advanced CPR, but they did not allow me to do so claiming these (equipment) are just for specialists, residents, and physicians, therefore nursing and anesthesia students cannot use them (p22)"

"We don't have an educator room in the hospital, I've been pursing it for ten years, but we haven't succeeded (p24)"

"If you want a class, they'll first give it to physician and we're in the next priority (p12)"

"I applied for a whiteboard, phone, and chair three semesters ago, they've still not even given them to us (p22)"

Another problem facing clinical education was that physicians prevented students from working with patients, which could disrupt the clinical learning environment.

A participant said:

"Anesthesiology residents say we won't let an anesthesiology student do intubation ( $p 7)^{\prime \prime}$ 
Another participant said:

"At the X hospital, physicians send us to bring them a specific medicine, bandage, but they don't let us work with the patient (p23)."

The presence of physicians unprofessionally treating nursing students and professors and preventing them from attending some wards of the hospital was another challenging clinical factor.

One participant said:

"An infectious diseases specialist came and shouted what are these students doing here, he was very disrespectful and said us to leave the ward ( $p 9)^{\prime \prime}$

Another participant said about the physicians who refuse to let the nursing educator attend the apprenticeship:

"The educator is capable but the physicians are stubborn and don't let them attend the ward anymore (p24)"

\section{Medical dominance, a barrier to nursing education advancement}

According to participants, the potential for nursing growth and development was very limited in the current physician-centered atmosphere. Here are some participants' statements:

"When there is no social justice and equal payment, the work is not done properly, nurses have a few solutions, one is leave their job, another one is to put their heads down and say nothing, which leads to stress and heart diseases and etc. (p16)"

"Nursing should advance as medicine does (p12)"

"Physicians don't allow us to achieve our goals, students say even if we get a master's degree, we're still considered as a servant at an inferior level, we want to resign (p5)"

"See I (as a physician) don't want to let nursing, laboratory sciences, radiology and the like to advance (p8) "

"They don't let students do research with the patient (p15)"

\section{Problems made by medical school in the path of nursing education}

Findings showed that nursing department experienced more medical dominance when it was located in the medical faculty. Here are some of the participants' experiences in this regard:

"Most of our problems originate from being deprived of an independent college, because we were part of the Faculty of Medicine (p11)"
"I haven't been asked to evaluate professors so far, why? Because we were dependant on the faculty of medicine (p3)"

"It was very difficult for us to make them understand our problems, to get facilities, to get practice mannequins was very difficult, we had no specialized books (p24)"

In cases where nursing departments were pursuing a reduction in bullying physicians' interventions in nursing education, there was problems made due to physicians' unprofessional responses and the education process was consequently disrupted.

A head of nursing department said:

"Because I eliminated the dominance of physicians over nursing theses, they say we are not going to teach (p12)"

Another participant said: "Due to the physicians' rage, a number of postgraduate students defended their dissertation without passing the course on diseases (p24)"

Overall, a physician-centered atmosphere discriminated between disciplines, weakened educational justice, and prevented non-medical disciplines, including nursing from achieving educational goals.

\section{Weakened educational status}

This category consists of two subcategories of "Denied Sabbatical" and "Weakened professional status".

\section{Denied sabbaticals}

According to the findings, the physiciancentered atmosphere prevented nursing professors from taking sabbaticals and it is the physicians who are provided with all such opportunities. Examples of the participants' statements in this regard are as follows:

"How is it possible to not to request for sabbaticals, but they have not yet considered this privilege for us (p2)"

"One of the weak points is that we have not been given any sabbaticals (p6)"

"No one has used any sabbaticals so far (p21)"

\section{Weakened professional status}

According to the findings, nursing education did not have a proper place in the system of medical education of Iran. Therefore, nursing professors did not have enough job satisfaction and were not willing to continue working. One participant said:

"All of my colleagues have left nursing, i.e. they are now PhD students in health psychology. They say we did it to leave nursing (p13)" 
Another participant stated:

"I am not saying that other disciplines are bad, but, here, I am the only one who has completed PhD in nursing (p17)"

Another participant said:

"Some schools became independent after us, they also built buildings for them, but they didn't do anything for nursing whose history dates back to longer time ago, that is they don 't care about it (p12)"

The weak position of nursing education, especially in non-governmental universities, has led authorities to allocate inadequate facilities and equipment for nursing education. Examples of participant statements are as follows:

"If the nursing budget was really spent on nursing, I would have made here a paradise (p19)"

"I myself pay for A4 pieces of paper utilized for administrative purposes (p13)"

"In fact, we sometimes face problems due to shortages of a piece of A4 paper (p18)"

"I myself pay for the adhesive tapes utilized for administrative purposes (p11)".

Lack of proper organizational position and power in nursing educational system leads to denied sabbaticals, educational opportunities, and ultimately reduced motivation and weak education process.

\section{Belittling nursing education in medical system}

This main category consists of three categories: "Triviality of nursing education problems for authorities and system", "University authorities who assume little responsibility are towards nursing" and "Poor university alignment with nursing education".

Triviality of nursing education problems for authorities and system

The findings of the study indicate that all the efforts made by the system were spent on medical education and that other fields, including nursing, were of little importance. One participant said:

"It seems like when I go to the university and say that what is the priority of nursing faculty on your list? They may say it is the last one and nursing as a major doesn't need an independent school and you should go to a hospital to receive trainings ( 211$)^{\prime \prime}$

A participant said about the triviality of not having access to the sites needed to teach IT to students by university officials:
"You know, when I wanted to introduce every site, I usually used a password, and a username I had from another university, etc. (p13)"

Another participant complained about not having an office at the college:

"My office was a classroom ( $p 8)$ "

The findings indicated shortage of nursing professors due to the fact that medical schools had been devoted the highest capacity to recruit faculty members. An example of the participants' statements is as follows: "We have little and limited share in invitation regarding faculty member recruitment ( 111$)$ "

"We want recruit faculty members, well, it's a challenge. Anyway, this will happen again (p6)"

"If authorities pay attention to shortage of professors, I would have recruited faculty members since 2016. Now, I have no faculty members in 2020, nursing doesn't matter to the authorities (p16)"

\section{Little responsibility towards nursing education on the part of the university}

According to the results, university managers did not feel sufficient responsibility for the problems of nursing education; consequently the problem solving process was slow. One participant said:

"If I hold ten-hour apprenticeship instead of 51-hour one, nobody says why I did it (p19)"

Another participant said:

"What happened now we have a college? It just puts pressure on us, now whatever we are going to do, they would say you have a college, you must do it (p1)"

\section{Poor alignment with nursing education on the part of the university}

According to the findings, the authorities did not provide adequate support for nursing education. In this regard, one participant said:

"If a physician does not like me as a student and my professor, head of the university would not support me and say this doctor is more important to me (p21)"

Another participant said:

"They don't care about the nursing school sufficiently (p10)"

Regarding the lack of support from the Vicechancellor for Research of the university in getting instructor room in the hospital, another participant said: "He says he will go for it and do something, but nothing has happened for 12 years (p24)"

About the absence of nursing professors' recruitment, a participant said: 
"They asked for professors' recruitment request from our school each year, but they didn't include it in the call for faculty member recruitment ( $p 3)^{\prime \prime}$

According to the experiences of the participants, the system and the university authorities assumed insufficient responsibility regarding the nursing education and they did not have enough effort to address the existing concerns.

\section{Discussion}

The aim of the present study was to explain medical dominance in nursing education from the perspective of the heads of nursing departments, which led to the emergence of the main theme as "Medical dominance in nursing education" and the three main categories of "University-centered physician education", "Weakened educational status", and "Belittling nursing education in medical system".

\section{Physician-centered university education}

The findings of this category confirm the special and superior position of physicians in the structure of the Ministry of Health and Medical Education of Iran, which manages the whole system with a medical focus and ignored the rights of professionals of other professions. This finding is consistent with the studies of Darvishpour et al. (2016), Rooddhegan et al. (2019), Gholami et al. (2019), and Moghaddasi et al. (2019) $(12,22-24)$. There is also a lot of evidence in this regard in other countries $(7,13,20$, 25-28)

The findings indicated the peak medical dominance and physician-centered atmosphere in clinical education due to the presence of physicians managing all clinical centers, so most clinical resources and facilities were available to them and nursing students were not allowed to use them. Numerous studies have confirmed severe discrimination between nursing and medical students in terms of distribution of welfare and educational facilities, including libraries, the Internet, and training classes $(6,18,29)$. Asirifi (2017) reported in a study in Ghana that students must purchase their own equipment such as a thermometer, gloves, a stethoscope, and hand towels for clinical learning (30). Therefore, policies need to be adopted to ensure that students enjoy real clinical rights in the classroom regardless of their discipline (31).

Physicians had unprofessionally and forcefully embarked on supervising nursing theses and had deprived nursing professors of their right. This action on the part of the physicians was in practice superficial and they did nothing but including their names as supervisors and readers on the cover of the theses. In other words, all the steps regarding the research processes of the theses were taken by the nursing professors. However, it was the physicians who were finally given the relevant privileges.

According to the study by Sena et al. (2017) who quoted from Cipolla \& Rocco (2014), physicians make up most of the permanent professors of nursing courses in Italian universities because academic jobs are controlled by commissions exclusively comprised by physicians and, so, nurses have less chance of achieving such jobs (7). Luzio's study (2008) indicates that physicians account for approximately half of the nurse teachers and theoretical education examiners as well as the heads of nursing schools in Germany (32).

Another example of medical dominance was the guardian-like interference of physicians in determining the duties assigned for the nurses and obtaining a license for establishing a master of arts major in nursing from the ministry without consulting the nursing department. According to the study by Sena et al. (2017), nursing courses and PHD research are also controlled by medical schools in Italy where specialist physicians make up the majority of structured teaching staff (7). Another example of physician-centered university education was the unprofessional interaction of physicians with nursing apprentices and the prevention of their entry into wards for apprenticeships.

Failure to pay full-time geographical payment (a salary that professors receive for extra-time attendance and teaching at the university) and the right to manage nursing professors was another example of physician's dominance. According to the Alubo study (2016), protesting the level of salary in Nigeria was one of the reasons for the various strikes of healthcare staffs due to medical dominance (25). Racic et al. (2019) also stated that Bosnian Herzegovina nurses, while dissatisfied with their level of independence, considered insufficient payment as a barrier to implementing advanced nursing education (33). According to the participants of the present study, the current problems of nursing education would be reduced and eliminated if nurses were provided with management positions. The findings suggest that the physician-centered structure prevents the use of nurses' knowledge in Iran, while the same individuals are highly successful when they migrate to other countries.

According to Goulten's (2019) study, one of the major concerns of nursing professors is the lack of practical application of students' knowledge (34). The study by Mamaghani et al. (2018) indicates a decrease in the academic motivation and carrier attitude of nursing students due to discrimination between them and medical students (6). Believing medical superiority over nursing has made nursing students less likely to enter inter-professional learning (20). Reed (2016) believe that physicians has prevented nurses from achieving maximum work potential due to their imperative policy (35). Rahmati et al. (2015) study showed non-use of nursing research in the clinical setting (36).

The findings also indicated that more staff were recruited for medical school and nursing schools had less access to staff. Moosavi et al. (2017) demonstrated in their study that management of academic centers should be prioritized and planned properly (37).

Nursing departments attended the medical school faced greater discrimination and injustice due to the inability to change conditions. The emergence of the "dominated nurses" category in the study by 
Rooddehghan et al. (2019) illustrates the inability of nurses to change their dominated status (24). According to the Kristoffersen and Friberg (2016), injustice causes aggressive behaviors, decreases the level of commitment and quality of work, and creates tension or conflict and quitting their jobs assigned by the organization. However, Iran's health system (2025) identifies justice and prosperity as the core values and aspirations of Iranian society (38).

\section{Weakened educational status}

This main category consists of two categories: "weakened professional standing" and "denied sabbatical". According to the findings, nursing education does not enjoy a proper position in Iranian higher education due to the hierarchical system, unbalanced distribution of power and medical dominance over the system. Nursing education could not have gained any professional opportunities such as sabbaticals under such passive and dominated situations. Considering that physicians who do not have a positive attitude to nursing are decision makers for sabbaticals in Iran, these sabbaticals are thus devoted to physicians and nursing professors were deprived of such valuable opportunity to learn about other countries' issues and share experiences with their peers. Alubo's (2017) study indicates that physicians regard management of educational centers as their right and believe that others do not qualify for such positions.

Alubo has referred to the appointment of physicians to ministerial positions and hospital management as one of the causes of protests made by Nigerian health care staff (25). According to the study by Cheraghi et al. (2015), the status of policymaking nurses in Iran has been promoted to the level of deputy minister but still lacks significant executive power (39). According to Lee (2016), hospitals that provide the most participatory management opportunity for nurses achieve better outcomes in terms of patient care, better quality of care, and nursing job (40).

The findings also indicated that one of the consequences of the weakened educational status was the abandonment of nursing discipline by nurses and some professors due to the fact that their dignity and professional value was under question. Students were dissatisfied claiming that they had worked as physicians' servants and lacked the support of the authorities; so, some considered a good option to the leave the nursing profession. Nursing professors also tried to escape the current situation by choosing nonnursing majors to continue their studies. Kristoffersen (2016) introduces the abandonment of organization by individuals as one way to combat discrimination and injustice (41). Valizadeh (2015) and Shohani (2019) stated in their studies that discrimination reduces work motivation and causes nurses to quit their jobs because of poor nursing status. $(10,42)$. The weakened nursing education status due to the medical dominance has created significant limitations and obstacles for the nursing education process, which require further reflection.

\section{Belittling nursing education in medical system}

This main category consists of three subcategories: "Triviality of nursing education problems for authorities and the system"," University authorities who assume little responsibility for nursing" and" little attention paid to nursing education by nursing authorities and the system ".

The findings indicated the triviality of nursing education problems for the organization, one of the examples of which was non-recruitment of professors for the nursing school. Some nursing schools have failed to make use of the annual recruitment capacity of university professors for several consecutive years, and have inevitably used invited professors. Such a trend was also in practice when providing educational facilities owing to the priority given to medical schools. According to Darvishpour et al. (2016), our organizational culture only supports and values physicians (22). The findings also revealed that the universities of medical sciences were primarily responsible for the training of physicians, so nursing education was almost abandoned, and the authorities only paid lip services; and they were only making promises. Failure to pursue the students' military services, providing facilities, and opposing the idea that nursing departments must be independent of unrelated colleges indicated that authorities evade part of their duties. The findings suggested that it was difficult for authorities to have a clear understanding of the challenges involved in nursing education. From the authorities' points of view, the value of the work of the heads of nursing departments is simply to provide a one-sheet training program per semester.

\section{Conclusion}

The findings indicate the superior position of physicians in the Ministry of Health and Medical Education of Iran. Physicians manage the systems at all micro and macro levels, including medical-focused education and ignore other disciplines, including nursing education. Nursing education would suffer from the lack of access to necessary educational facilities, especially in health care centers, and has failed to progress under such a situation. The triviality of nursing education for authorities has led to the abandonment of nursing education, the frustration of faculty and students, the failure to realize their potential, and ultimately the weakness and passiveness of nursing education.

\section{Acknowledgments}

This study is part of the author's PhD dissertation in Nursing approved by the Ethics Committee of Baqiyatallah University of Medical Sciences numbered 9121151003. Hereby, the authors would like to express his thanks and gratitude to the respected university officials who funded this study. The authors would like to sincerely thank the participants who shared their experiences with the researchers as well as the respected colleagues who assisted the researchers in the process. 


\section{Conflict of Interest}

There is no conflict of interest to be declared.

\section{References}

1. Leal Filho W, Vargas VR, Salvia AL, Brandli LL, Pallant E, Klavins M, et al. The role of higher education institutions in sustainability initiatives at the local level. Journal of Cleaner Production. 2019;233;1004-15.

2. Yuan X, Zuo J. A critical assessment of the Higher Education For Sustainable Development from students' perspectives-a Chinese study. Journal of Cleaner Production. 2013;48;108-15

3. Pucciarelli F, Kaplan A. Competition and strategy in higher education: Managing complexity and uncertainty. Business Horizons. 2016;59(3); 311-20

4. Heidari A, Mazloum SR, Karimi Moonaghi H, Mojalli M, Hosseini Shahidi L, Namder Areshtanab $\mathrm{H}$. Educational challenges ahead of nursing from the perspective of faculty members of Mashhad University of Medical Sciences. Journal of Advances in Medical Education \& Professionalism. 2013;1(4);125-8

5. Khodaveisi M, Pazargadi M, Yaghmaei F, Bikmoradi A. Identifying challenges for effective evaluation in nursing education: A qualitative study. Journal of research in medical sciences: the official journal of Isfahan University of Medical Sciences. 2012;17(7);710-17

6. Mamaghani EA, Rahmani A, Hassankhani $\mathrm{H}$, Zamanzadeh V, Campbell S, Fast $\mathrm{O}$, et al. Experiences of Iranian nursing students regarding their clinical learning environment. Asian nursing research. 2018;12(3);216-22

7. Sena B. Professionalization without autonomy: the Italian case of building the nursing profession. Professions and Professionalism. 2017;7(3);e1900e2112

8. Sidhu S, Park T. Nursing curriculum and bullying: An integrative literature review. Nurse education today. $2018 ; 65 ; 169-76$

9. Krau SD. Social justice: a basis for health care delivery. Nursing Clinics. 2015;50(3);xiii-xv

10. Valizadeh L, Zamanzadeh V, Irajpour A, Shohani M. " Discrimination", the Main Concern of Iranian Nurses over Inter-Professional Collaboration: an Explorative Qualitative Study. Journal of caring sciences. 2015;4(2);115.-123

11. Dubrosky R. Iris Young's Five Faces of oppression applied to nursing. Nurs Forum. 2013;48(3);205-10.

12. Moghaddasi H. Globally Improving the Quality of Care: The Role of WHO in Controlling Doctor Dominance in the World. JOJ Nurse Health Care. 2019;10(1);1-3

13. Toth F. Sovereigns under Siege. How the medical profession is changing in Italy. Social science \& medicine. 2015;136;128-34

14. Rooddehghan Z, ParsaYekta Z, Nasrabadi AN. Nurses, the oppressed oppressors: a qualitative study. Global journal of health science. 2015;7(5);239-45
15. Fawaz MA, Hamdan-Mansour AM, Tassi A. Challenges facing nursing education in the advanced healthcare environment. International journal of Africa nursing sciences. 2018;9;105-10

16. Hutchison JS. Anti-oppressive practice and reflexive lifeworld-led approaches to care: a framework for teaching nurses about social justice. Nursing research and practice. 2015;1-5

17. Eka NGA, Chambers D. Incivility in nursing education: A systematic literature review. Nurse education in practice. 2019;45-54

18. Jamshidi N, Molazem Z, Sharif F, Torabizadeh C, Najafi Kalyani M. The challenges of nursing students in the clinical learning environment: A qualitative study. The Scientific World Journal. 2016;1-7

19. Mohebbi Noubandegani Z, Rambod M, Hashemi F, Mohammadi H, Najafi Dolatabad S, Setoudeh G. View point of the nursing students on challenges in clinical training, Shiraz, Iran. Hormozgan Medical Journal. 2012;16(5);415-21

20. Sollami A, Caricati L, Mancini T. Does the readiness for interprofessional education reflect students' dominance orientation and professional commitment? Evidence from a sample of nursing students. Nurse education today. 2018;68;141-5

21. Allari R. Nursing students' experiences of work place violence during clinical placements: a qualitative study. GARJMMS. 2016;5(8);228-36

22. Darvishpour A, Joolaee S, Cheraghi MA, MokhtariLakeh N. Iran's health policymakers' views on barriers and facilitators of nurse prescribing in their context: A qualitative study. Iranian journal of nursing and midwifery research. 2016;21(3);297-305

23. Gholami M, Saki M, Hossein Pour AH. Nurses' perception of empowerment and its relationship with organizational commitment and trust in teaching hospitals in Iran. Journal of nursing management. 2019;27(5);1020-9

24. Rooddehghan Z, ParsaYekta Z, Nasrabadi AN. Equity in nursing care: A grounded theory study. Nursing ethics. 2019;26(2);598-610

25. Alubo $\mathrm{O}$, Hunduh V. Medical dominance and resistance in Nigeria's health care system. International Journal of Health Services. 2017;47(4);778-94

26. Tang CJ, Zhou WT, Chan SWC, Liaw SY. Interprofessional collaboration between junior doctors and nurses in the general ward setting: A qualitative exploratory study. Journal of nursing management. 2018;26(1);11-8

27. Weaver S, Gull B, Ashby J, Kamimura A. An Analysis of Oppression and Health Education for Underserved Populations in the United States: The Issues of Acculturation, Patient-Provider Communication, and Health Education. Journal of Education and Practice. 2017;8(15);150-5

28. Zhu J, Rodgers S, Melia KM. A qualitative exploration of nurses leaving nursing practice in China. Nursing open. 2015;2(1);3-13 
29. Shadadi H, Sheyback M, Balouchi A, Shoorvazi M. The barriers of clinical education in nursing: A systematic review. Biomedical Research. 2018;29(19);3616-23

30. Asirifi M, Ogilvie L, Barton S, Aniteye P, Stobart $\mathrm{K}$, Bilash $\mathrm{O}$, et al. Assessing challenges of clinical education in a baccalaureate nursing program in Ghana. Journal of Nursing Education and Practice. 2017;7(10);109-18

31. Zarandi FM, Raiesifar A, NabiAmjad R, Masoumi M, Taghinezhad F. Explanation of educational justice status in the clinical nursing education in Iran: the content analysis of previous studies. International Journal of Medical Reviews. 2015;1(4);169-73

32. Luzio Gd. Medical dominance and strategic action: the fields of nursing and psychotherapy in the German health care system. Sociology of health \& illness. 2008;30(7);1022-38

33. Racic M, Pavlovic J, Hadzivukovic N, Ivkovic N. Perceptions, attitudes, and expectation of baccalaureate nurses toward position of nursing in Bosnia and Herzegovina. The International journal of health planning and management. 2019;34(2);e1223-e35

34. Dağ GS, Hülya Fırat Kılıı̧, Görgülü RS. Diffculties in Clinical Nursing Educaton: Views of Nurse Instructors. Int Arch Nurs Health Care. 2019;5(1);1-9
35. Reed PG. Epistemic Authority in Nursing Practice vs. Doctors' Orders. Nursing science quarterly. 2016;29(3);241-6

36. Rahmati Sharghi N, Khosravan S, Mansoorian MR, Ekrami A. Academic training and clinical placement problems to achieve nursing competency. J Adv Med Educ Prof. 2015;3(1);15-20

37. Moosavi A, Mohseni M, Ziaiifar H, AzamiAghdash S, Gharasi Manshadi M, Rezapour A. The Quality of Educational Services from Students' Viewpoint in Iran: A Systematic Review and Metaanalysis. Iran J Public Health. 2017;46(4);447-55

38. Rostamigooran N, Esmailzadeh H, Rajabi F, Majdzadeh R, Larijani B, Vahid Dastgerdi M. Health System Vision of Iran in 2025. Iranian J Publ Health. 2013;42(1);18-22

39. Cheraghi M, Ghiyasvandian S, Aarabi A. Iranian Nurses' Status in Policymaking for Nursing in Health System: A Qualitative Content Analysis. The Open Nursing Journal. 2015;9;15-24

40. Kutney-Lee A, Germack H, Hatfield L, Kelly S, Maguire P, Dierkes A, et al. Nurse Engagement in Shared Governance and Patient and Nurse Outcomes. J Nurs Adm. 2016;46(11);605-12

41. Kristoffersen M, Friberg F. Remaining in the nursing profession: The relevance of strong evaluations. Nurs Ethics. 2018;25(7);928-38

42. Shohani M. The consequences of nurses' endeavours to overcome inter-professional dis crimination. Nurse Ethics. 2019;26(7-8);2058-70. 